\title{
A INTERNACIONALIZAÇÃO DAS EMPRESAS FRIGORÍFICAS BRASILEIRAS
}

\author{
Gabriel Furlan Coletti \\ Universidade Estadual Paulista "Júlio de Mesquita Filho" - UNESP/FCLAr \\ Kleber Alves da Silva Franculino \\ Universidade Estadual Paulista "Júlio de Mesquita Filho" - UNESP/FCLAr \\ Mariana Gonçalves Mota \\ Universidade Estadual Paulista "Júlio de Mesquita Filho" - UNESP/FCLAr
}

\begin{abstract}
Resumo: Tem-se observado um crescente processo de internacionalização das empresas pelo mundo, fato que ocorre de forma mais acentuada nas empresas oriundas de mercados emergentes. O objetivo deste trabalho é avaliar o poder explicativo das teorias de internacionalização, considerando o processo de expansão internacional das empresas da indústria de carnes brasileiras. O trabalho se inicia com um levantamento bibliográfico sobre as principais teorias de internacionalização, sendo posteriormente levantados os movimentos de expansão das empresas brasileiras. Após a análise dos dados e a relação com as teorias, constatou-se que as teorias de internacionalização tem grande poder explicativo sobre os casos estudados, em especial pela convergência de pontos específicos do referencial teórico com as singularidades dos casos.
\end{abstract}

Palavras-chave: Internacionalização; Indústria de Carnes Brasileira; Expansão.

\begin{abstract}
Has been observed an increasing internationalization process from companies around the world, which occurs more sharply in companies from emerging markets. This paper aims to evaluate the internationalization theories' explanatory power, considering the Brazilian meat industry international expansion. The paper is started with a literature review on the main internationalization theories, subsequently the Brazilian meat companies expansion movements are surveyed. After the data analysis and relation to the theories, it was found that the internationalization theories have great explanatory power on the studied cases, specially by the convergence of specific points from the theoretical framework with cases' singularities.
\end{abstract}

Keywords: Internationalization; Brazilian Meat Industry; Expansion.

\author{
Classificação JEL: F23
}




\section{Introdução}

O setor frigorífico mostra-se como portador de grandes potencialidades, dado o tamanho da demanda global por alimentos in natura e alimentos processados à base de carne (BELK et al, 2014), assim como os mercados em processo de abertura para as exportações brasileiras, como o asiático. As aquisições internacionais permitem às empresas brasileiras diversificar suas estratégias (ROVAI; PISCOPO; MACCARI, 2013), possibilitando o contorno de barreiras fitossanitárias impostas ao país por mercados consumidores, como Rússia e Europa, por meio da produção de tipos diferentes de carnes e melhorias tecnológicas, que resultam num produto final de maior qualidade.

O processo de expansão das empresas frigoríficas brasileiras, além de veloz e agressivo (SPOHR; SILVEIRA, 2012), resultou na consolidação do país na posição de maior exportador de carne bovina do mundo, dominando, inclusive, a produção nos Estados Unidos da América (CLYMA, 2014). O governo brasileiro teve papel importante neste processo, financiando parcialmente, por meio de empréstimos e compra de participações acionárias, as atividades das multinacionais brasileiras no exterior.

Este trabalho tem como objetivo o estudo da internacionalização das empresas multinacionais brasileiras do setor frigorífico e a aplicabilidade das teorias de internacionalização aos casos selecionados. As empresas estudadas são JBS, Marfrig, BRF e Minerva Foods. Os dados para a análise são os movimentos de investimento no exterior das empresas, obtidos através de levantamentos em relatórios de investimentos das aquisições das empresas selecionadas. As teorias de internacionalização são obtidas por levantamento bibliográfico sobre o tema.

\section{Teorias de Internacionalização via Investimento Direto Estrangeiro}

O IDE tem recebido mais atenção pelos pesquisadores desde o período pós-segunda guerra mundial, sendo considerado uma importante ferramenta para o desenvolvimento dos países, especialmente ao considerar-se os países em desenvolvimento. Após diversos estudos sobre o tema, resultando em diversas abordagens diferentes (CANTWELL, 2000), constatou-se que os efeitos do IDE são complexos e diversificados. O desenvolvimento econômico que envolve IDE abrange aspectos ligados a transbordamentos tecnológicos, aumentos de produtividade e competitividade. Esses elementos constituem fatores de fundamental importância para a firma, especialmente em seu nível estratégico (PEARCE; PAPANASTASSIOU, 2009). Em termos de desenvolvimento nacional, o IDE tem potencial para promover a geração de empregos, além do aumento nas exportações, acesso à mercados internacionais e moedas estrangeiras (NARULA, 2009).

O IDE pode ser representado pelo fluxo e estoque de capitais entre países, de origem e de destino, assim como pelas receitas obtidas destes investimentos. Um dos aspectos principais de estudo do IDE é a tentativa de explicar as motivações para investir além das fronteiras nacionais, na perspectiva do investidor, assim como seus desdobramentos tanto no país de origem quanto no país de destino do investimento. Por sua vez, o investidor, a empresa multinacional (EMN), pode ser entendido como um empreendimento que controla e gerencia atividades econômicas, por meio de plantas, localizadas em pelo menos dois países (CAVES, 2007).

\subsection{A Teoria do Poder de Mercado}

Hymer (1960) analisou os investimentos financeiros (portfólio) e a teoria neoclássica, observando que os fatores determinantes para a decisão de investimento em outros mercados era a diferença entre as taxas de juros e incerteza que permeia a economia internacional. Ao considerar o investimento de firmas norte-americanas para negócios e produção em diversos outros países do mundo, o autor constata a necessidade de classificar os diferentes tipos de investimentos realizados, 
dividindo assim o IDE em investimentos de portfólio (financeiros) e investimentos diretos (produção).

Os fatores relacionados à diferenciação dos tipos de investimento são a natureza de sua motivação e as consequências para a firma e para o contexto macroeconômico. Para Hymer, o critério de diferenciação é o controle, ou seja, o investimento direto confere à firma o controle sobre as atividades produtivas no exterior, enquanto o mesmo não ocorre com o investimento de portfólio. Apesar de o investimento direto representar um fluxo de capitais, ele não pode ser analisado de modo idêntico ao movimento de investimentos de portfólio, havendo diferenças consideráveis nos determinantes e motivações entre ambos.

Para o autor, o que determina o IDE é a expectativa de crescimento de poder de mercado e lucros maiores, mesmo havendo custos e riscos extras associados à este movimento. Para que este cenário seja possível, a existência de imperfeições de mercado é necessária. Estas imperfeições são estruturais e podem assumir formas como economias de escala interna e externa, imperfeições nos mercados de bens e/ou fatores e interferência do governo nas relações de produção e/ou comércio.

Com estes pressupostos de imperfeições, Hymer apresenta duas motivações para a realização de IDE: Na primeira, a firma possui características específicas que podem ser exploradas de maneira lucrativa no exterior (ou potencial para a criação de novas vantagens competitivas). No segundo caso, se já existem firmas concorrentes ou tentando entrar no mercado doméstico, ocorrerá uma situação de conflito. A firma, neste caso, procura eliminar esta situação por meio da aquisições de unidades de produção no exterior, levando à um aumento em seu poder de mercado, aumentando as imperfeições do mercado como um todo.

\subsection{Teoria do Ciclo de Vida do Produto}

Segundo Vernon (1966), existe uma relação entre o aumento da produção e a localização da mesma. A produção assume, gradativamente, uma padronização, enquanto os custos envolvidos se tornam mais relevantes. Os custos induzem as firmas a considerar alternativas mais baratas envolvendo, possivelmente, outras localidades. Uma vez que a nova localidade apresente vantagens em termos de custo, se comparadas à produção e comercialização doméstica (incluindo custos de transportes), a firma encontra motivação suficiente para a realização do IDE.

A teoria proposta por Vernon (1966) aponta que uma inovação acontece em mercados que buscam novos produtos, nos quais a renda per capita e o poder de compra são mais elevados. Este fato influencia a busca por inovações. Além disso, maior renda per capita possibilita a venda de produtos com maior valor agregado. Depois da introdução deste novo produto e sua comercialização inicial, há um aumento na demanda, fazendo com que haja um processo de padronização, observando-se que a padronização não impede que a diferenciação do produto se mantenha de forma contínua, especialmente ao considerarmos a crescente competição.

O contexto da análise do autor se deu em um período especifico do pós guerra, caracterizado pela entrada das empresas norte-americanas no mercado europeu. Considerando a indústria de transformação, Vernon estabeleceu quatro ciclos de produção: inovação, crescimento, maturidade e declínio. No ciclo da inovação, há a criação de novos produtos para o mercado interno. Quando ocorre o crescimento da produção, é iniciada a exportação de excedentes para mercados externos, o que indica a presença de vantagens tecnológicas do exportador frente a concorrência internacional. À medida que passa a existir uma padronização da produção, há também uma replicação destes produtos por outras empresas, via difusão tecnológica. Esse ciclo indica que o produto está alcançando um grau maior de maturidade. No período de declínio, as empresas europeias já possuíam domínio tecnológico para replicar os produtos importados, induzindo as empresas norteamericanas a instalar unidades produtivas na Europa. Desse modo, o país que antes era exportador, ao realocar sua produção, passa a exercer um papel de importador, devido a possibilidade de 
realizar as atividades produtivas em outro país ou região que confere vantagens em termos de custo e/ou regulação.

\subsection{Teoria da Reação Oligopolista}

A Teoria da Reação Oligopolista, de Frederick Knickerbocker (1973) é um modelo para explicar como o comportamento de algumas firmas leva ao IDE e como elas se relacionam com a estrutura de mercado. Ao observar as características do mercado, o autor sinaliza que no período pós-guerra, as firmas se tornaram mais internacionalizadas. Em um segundo momento, as indústrias de um mesmo setor direcionam seus investimentos para os mesmos países. Logo, as empresas envolvidas em expansões internacionais pertencem a mercados com estruturas oligopolistas.

Para o desenvolvimento deste modelo, Knickerbocker assume uma estrutura de mercado oligopolista, com poucos concorrentes. Os produtos destas firmas são substitutos próximos, com uma interdependência entre as políticas competitivas das empresas. Esta interdependência leva à um padrão de ação e reação para melhorar sua posição frente à seus concorrentes (movimento agressivo) ou alcançá-los, numa forma de minimizar os riscos (movimento defensivo).

Este cenário de movimentos e repetições é representado pela expressão "siga o líder". Um exemplo desse fenômeno consiste em uma firma que investe em um país para aumentar sua fatia de mercado. Logo após este movimento, outra firma oligopolista rival investe naquela mesma localidade a fim de ocupar uma parcela daquele mercado. Existe a possibilidade da primeira firma obter vantagens de seu movimento agressivo e utilizá-las contra seus rivais. A firma utiliza essas vantagens para alterar o equilíbrio competitivo e gradualmente eliminar seus concorrentes. Isto motiva as outras empresas à se movimentarem de forma defensiva, em reflexo do primeiro investimento.

\subsection{Teoria da Internalização}

Desenvolvida por Buckley e Casson (1976), a partir dos estudos de McManus (1972), a Teoria da Internalização buscou compreender os efeitos da centralização das etapas produtivas sobre o desempenho das empresas. Primeiramente, a análise considerou a maximização dos lucros num ambiente de mercado imperfeito. Se o mercado de bens intermediários for imperfeito, há um incentivo para a criação de um mercado interno, controlando etapas da produção.

Estas condições de imperfeições são transacionais, e estão relacionadas aos altos custos de transporte, existência de barreiras comerciais tarifárias e não-tarifárias, assimetrias de informação, entre outras. Desse modo, são caracterizadas por condições que aumentam os custos de transação, que conduzem a realização do IDE voltado para a internalização de etapas produtivas de bens intermediários.

Segundo Buckley e Casson (1976), as companhias transnacionais organizam suas atividades internas de modo que sejam desenvolvidas vantagens específicas. A exemplo disso, ressaltam duas áreas principais para o processo de internalização: os mercados de produtos intermediários, como citado acima, e mercados relativos ao conhecimento, em virtude da dificuldade de transferência de ativos intangíveis específicos à firma.

A internalização pode ocorrer por meio de dois tipos de integração: vertical e horizontal. Segundo Caves (1971), caso uma firma opte por investir horizontalmente, a mesma deve ter capacidades especificas que lhe confira vantagens sobre as firmas domésticas no mercado de destino. Estas firmas locais, possuem vantagens especificas, resultado da sua condição de residente, levando a empresa entrante a ponderar - frente as vantagens de ambas - se o IDE é mais lucrativo do que exportar ou licenciar. 
O IDE voltado para a integração vertical das empresas exige uma experiência prévia com integração vertical em nível nacional. Deve ser considerado o trade-off que resulta dos custos de transação entre produção interna e arranjos contratuais com firmas externas.

Como determinante do investimento direto, Caves considera uma estrutura de mercado oligopolista, na qual existe uma diferenciação de produtos (por meio de alterações físicas, marcas, marketing) que possam ser sustentadas por direitos de propriedade e barreiras de alto custo à imitação física. Também devem ser analisados aspectos como habilidades organizacionais, custos de transporte e tarifas, e atividades de pesquisa e desenvolvimento.

\subsection{O Paradigma Eclético (OLI)}

As proposições de Dunning $(1973,1980,1988)$ retratam que para ocorrer a produção em mercados estrangeiros, alguma condições devem ser satisfeitas. A firma que realizar IDE deve conter habilidades e ativos tangíveis e intangíveis que possibilite competir com as firmas domésticas no país de destino, uma vez que as empresas locais já detém vantagens de conhecimento e de experiência com relação ao mercado. Outra condição que estimula a produção em novos mercados é o fato da nova localidade apresentar condições específicas que geram maior lucratividade. O autor argumenta que o IDE deve ser mais lucrativo do que vender, arrendar ou licenciar as habilidades e conhecimentos.

Segundo Dunning, essas condições podem representar vantagens de propriedade (O ownership), localização (L - location) e internalização (I - internalization). O autor considera que as vantagens de propriedade são aquelas específicas a um determinado empreendimento. Patentes, segredos comerciais, marcas registradas, economia de escala, acesso à mercados e insumos, conhecimento técnico-produtivo, menor custo de insumos e barreiras sociais são exemplos de vantagens de propriedade.

As vantagens de localização são aquelas específicas à uma determinada localidade ou país, que a tornam mais atrativa como destino de investimento estrangeiro. A empresa ao usufruir dos benefícios da localidade pode obter ganhos como baixos custos de transporte e de trabalho, proximidade do mercado consumidor, marcos regulatórios favoráveis, infraestrutura, políticas governamentais, imagem local etc.

Quanto a internalização, as vantagens se originam dos benefícios de se produzir internamente insumos para a firma. Isso possibilita a superação de imperfeições de mercado e a redução de custos de transação. Os benefícios da internalização provém da superação de problemas como diferentes regulações sobre produtos semelhantes entre países, instabilidades econômicas e políticas, além problemas logísticos com fornecedores.

\subsection{Processo de Internacionalização em Estágios}

Johanson e Wiedersheim-Paul (1975) e Johanson e Vahlne (1977, 1990), buscaram analisar os estágios do processo de internacionalização de empresas, assim como a sequência de entrada em outros países. Este modelo é constituído por uma sequência de tempo, desenvolvida num padrão linear, no qual os elementos de determinado estágio de internacionalização formam o insumo necessário ao próximo estágio. Para os autores, as etapas de internacionalização poder ser ilustradas por exportação via representantes, seguido de subsidiária de vendas e, por fim, subsidiária de produção.

Um aspecto observável da internacionalização corresponde ao modo como a firma se relaciona com o país/mercado de destino. Essa relação pode ser representada pela proximidade psíquica (cultural) entre ambos. Segundo os autores, quanto mais parecidas as duas nações forem em aspectos como linguagem, cultura, educação, práticas empresariais e desenvolvimento 
industrial, mais cedo ocorre o processo de internacionalização. Considerando o fato de que as distâncias físicas e psíquicas estão correlacionadas.

Ao iniciar um processo de internacionalização, uma empresa procura se expandir para países com características psíquicas semelhantes. Os países que apresentam menor grau de semelhança são alvo de internacionalização posterior, seguindo a mesma condição sequencial e linear. Dessa forma, este processo se inicia em países com menor distância psíquica e física, se difundindo para países com maiores distâncias (IETTO-GILLIES, 2012). Sendo um processo linear, as decisões de investimento são incrementais, considerando os recursos investidos, os conhecimentos gerais e específicos sobre o mercado estrangeiro e o desempenho dos negócios atuais.

\section{IDE - Países desenvolvidos e países em desenvolvimento}

O fenômeno da internacionalização, nas últimas décadas, deixou de ser exclusivo dos países desenvolvidos. Segundo Spohr e Silveira (2012), em termos de histórico e competição, as EMN de países emergentes estão em um contexto muito diferente das firmas tradicionais. Ainda não há, na literatura, um consenso sobre o modo como diferem-se as novas multinacionais das EMN tradicionais, considerando-se os perfis e estratégias. Assim, os países em desenvolvimento têm apresentado taxas crescentes de fluxo de saída de IDE em termos globais, conforme demonstrado no gráfico abaixo:

Gráfico 1: Investimento estrangeiro direto, fluxos de saída de capital, 1998 - 2012

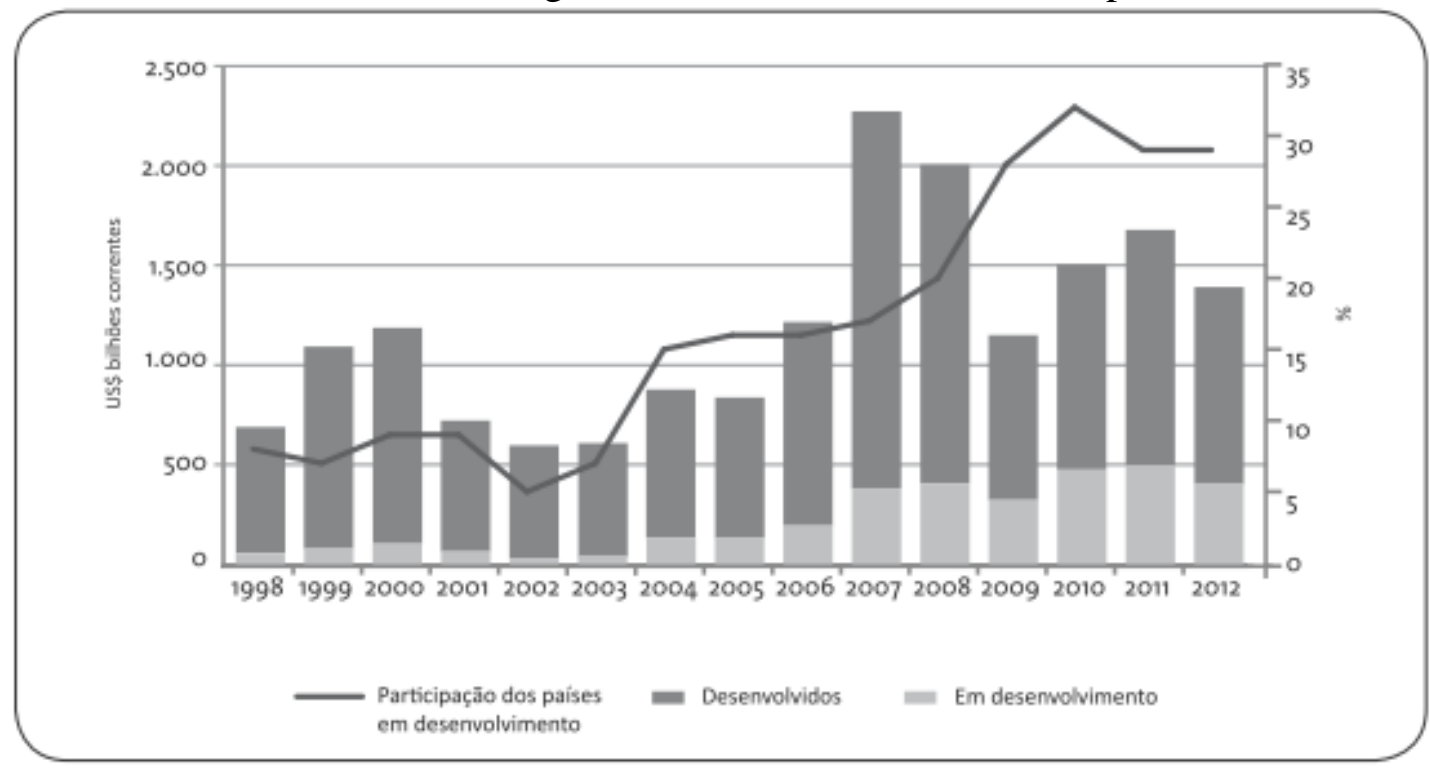

Fonte: Pimentel et al. (2014).

Apesar de apresentar uma participação crescente nos fluxos de saída de IDE, as empresas de países em desenvolvimento possuem características específicas, que condicionam suas motivações e estratégias de internacionalização. Ao nível da empresa, o efeito “país de origem” restringe o alcance dos produtos dessas firmas no novo mercado, pois representa a desconfiança sobre a qualidade dos bens produzidos por uma firma de país em desenvolvimento. Para minimizar esse efeito, a internacionalização tende a ocorrer via parcerias e aquisições de marcas já consolidadas. No entanto, essas mesmas firmas possuem vantagens se o destino do investimento é outro país em desenvolvimento, uma vez que o conhecimento e as experiências já adquiridas por atuar em mercados menos desenvolvidos pode ser aproveitado (KUMAR; SINGH, 2008). 
Por outro lado, as empresas de países em desenvolvimento também podem buscar se internacionalizar sem possuir vantagens competitivas. Conforme apontam Dunning, Kim e Park (2008), essas empresas podem, por meio da internacionalização, adquirir novas competências tecnológicas e organizacionais. Desse modo, a internacionalização das firmas pode contribuir com o processo de convergência (catch-up) dos países em desenvolvimento (PIMENTEL et al, 2014). A busca por ativos não disponíveis, nesse sentido, pode ser um forte motivador para a internacionalização das empresas.

Um elemento importante a ser destacado é a dificuldade que pode ser encontrada na obtenção de recursos financeiros para as operações de internacionalização. Além disso, problemas institucionais e macroeconômicos podem gerar problemas para as empresas se internacionalizarem (PIMENTEL L, 2014). Nesse ambiente, a facilitação do processo por meio de políticas de apoio e empréstimos por parte de bancos de investimento pode ser o modo como uma empresa de país em desenvolvimento pode se internacionalizar.

\section{O Setor de Carnes Brasileiro}

Segundo o Anualpec (2015), o Brasil é líder mundial na exportação de carne bovina, com uma cadeia pecuária que vem recebendo investimentos, em parceria com o governo federal, buscando ganhos em escala, melhoramentos genéticos, aumento de produtividade e novas tecnologias. Isto se dá graças à novos acordos internacionais e pela constante busca pela evolução dos conceitos e da sanidade geral dos rebanhos, que totalizam mais de 208 milhões de animais.

A pecuária de corte representa cerca de 12\% do Produto Interno Bruto (PIB) do agronegócio nacional, que teve como resultados em 2014, a produção de pouco mais de 10 milhões de toneladas de carne bovina, das quais exportou 2,09 milhões de toneladas, resultando num faturamento de US\$ 7,2 bilhões. Para realizar a análise proposta neste trabalho, serão considerados os quatro maiores frigoríficos brasileiros, dado sua capacidade de investimento, tanto no Brasil quanto no exterior, sendo estas JBS, Marfrig, BRF e Minerva Foods.

\subsection{JBS}

Iniciando seu processo de internacionalização em 2005, a JBS adquiriu a empresa frigorífica argentina Swift Armour, por US\$ 200 milhões. Em 2006, a empresa adquiriu mais duas empresas argentinas do setor frigorífico: a Venado Tuerto (US\$ 15,75 milhões) e Pontevedra (US\$ 27 milhões). Em 2007, a JBS fez duas grandes aquisições: a primeira foi a compra da norte-americana Swift Foods, pelo valor de RS 1,13 bilhão, e a segunda foi a aquisição da italiana Inalca, por $€ 225$ milhões. Em 2008, o grupo comprou a norte-americana Smithfield Beef Group, produtora e processadora de suínos, por US\$ 565 milhões. Também houve a tentativa de aquisição National Beef, que acabou sendo impedida pelo governo americano por alegações relativas à concentração de mercado. Neste ano também houve a expansão da empresa para outro continente, com a compra da australiana Tasman, no mercado de bovinos e animais de pequeno porte (ovinos e vitela), por US\$ 150 milhões.

Já em 2009 houve a aquisição de três outras empresas: a Pilgrim's Pride, a Bertin e a Tatiara Meat Company. O primeiro caso é uma empresa norte-americana, no mercado de frangos, no valor de US\$ 800 milhões; o segundo caso é a compra do frigorífico brasileiro Bertin, de bovinos; e o terceiro é a aquisição da Tatiara Meat Company, processadora de ovinos, por US\$ 27,5 milhões.

Em 2010, a JBS comprou a australiana Beef Rockdale por US\$ 37,3 milhões. Também comprou uma unidade de confinamento nos Estados Unidos, a McElhaney Cattle, por US\$ 24 milhões. Para aumentar sua gama de operações na Europa, a empresa brasileira adquiriu a Toledo Group, de processamento bovino, por $€ 11$ milhões, na Bélgica. E expandindo suas operações na 
Amárica do Norte, comprou a Weddel, empresa canadense de enlatados e processamento de alimentos, por US\$ 3,75 milhões.

No ano de 2011, houve a ruptura com o grupo Cremonini, com o qual a JBS era sócia na empresa Inalca. Assim, a empresa brasileira fez a aquisição da Rigamonte na Itália, no mercado de carnes processadas, por $€ 50$ milhões. Em 2012, houve o arrendamento com opção de compra da Frangosul, quando a JBS inicia sua operação com suínos e aves no Brasil. Adquirindo posteriormente a Agroveneto, de criação e processamento de frangos no Brasil, por R\$ 128 milhões. Em 2013, a JBS realizou uma de suas maiores aquisições, comprando a Seara Brasil e a Zenda (couros/Uruguai) por R\$ 5,8 bilhões. Também fez a aquisição do Frigorífico Independência, brasileiro, por R\$ 268 milhões.

Já em 2014 houve a tentativa de aquisição da norte-americana Hillshire Brands, resultando na aquisição pela Tyson Foods. A JBS comprou, neste ano, o Grupo Primo Smallgoods, empresa australiana de processamento de alimentos, por US\$ 1,125 bilhão. No Brasil fez duas aquisições para o mesmo período: a Massaleve (Massas e pratos prontos) por R\$ 258,6 milhões, e a Frinal, criação e processamento de frangos, por R\$ 103,5 milhões.

No ano de 2015, a JBS anunciou a aquisição da Moy Park, consolidando sua estrutura de operações na Europa, na divisão de frangos e processados, por US\$ 1,212 bilhão, sediada na Irlanda. Também adquiriu a divisão de suínos da norte-americana Cargill (Cargill Pork), por US\$ 1,45 bilhão. A empresa brasileira adquiriu o grupo brasileiro Big Frango por R\$ 430 milhões. Também anunciou a planejamento da construção de um novo frigorífico no Paraguai, com orçamento previsto de US\$ 100 milhões.

Diversificando suas operações e investimentos, ainda em 2015, a JBS comprou a Alpargatas, empresa brasileira de calçados, por R $\$ 2,67$ bilhões. A empresa também fez uma oferta de US\$ 42 milhões para a aquisição da Scott, empresa neozelandesa de robótica (automação de processamento de alimentos). A JBS também realiza operações no mercado financeiro, no qual obteve bons resultado com operações de hedge, protegendo-se contra a desvalorização cambial; neste tipo de operação, a empresa chegou a ter seu lucro reduzido em $\mathrm{R} \$ 2$ bilhões no segundo trimestre, mas se recuperou com novos resultados da operação, que lhe proporcionaram um lucro de R 15 bilhões.

Atualmente a JBS tem diversas áreas de atuação, compreendendo desde setores diretamente ligados ao setor frigorífico, como couros e laticínios, até atividades mais diversificadas, como higiene e limpeza, colágeno, ambiental, biodiesel, embalagens metálicas, envoltórios, trading e transportes (JBS, 2015).

\subsection{Marfrig}

A Marfrig é atualmente a terceira maior produtora de bovinos do mundo, com presença de seus produtos em mais de 110 países, realizando atividades de produção, processamento, industrialização, venda e distribuição de alimentos. A empresa brasileira tem 80 unidades de produção, centros de distribuição e escritórios, em 16 países da América do Sul, América do Norte, Europa, Oceania e Ásia, com uma rede de 45 mil colaboradores, sendo a sexta empresa brasileira mais internacionalizada e a empresa do setor de carnes mais internacionalizada, de acordo com relatório da Fundação Dom Cabral (FDC, 2015).

Em 2006 a empresa efetuou a aquisição dos frigoríficos Tacuarembó (Uruguai), Argentine Breeders \& Packers (AB\&P - Argentina) e Frigoclass (Brasil) por US\$ 70 milhões. Consolidando sua expansão no mercado sul-americano, a Marfrig também adquiriu a Inaler e o frigorífico Elbio Perez Rodriguez, ambos do Uruguai, por US\$ 25 milhões cada, e oficializou uma joint venture com a Quinto Cuarto, empresa de trading chilena.

Já no ano de 2007 houve as aquisições da Best Beef e da Estancia del Sur, frigoríficos argentinos, por US\$ 39,3 milhões. Outra aquisição argentina foi a processadora de alimentos 
Quickfood, por US\$ 141 milhões. Também realizou a aquisição da Estabelecimientos Colonia, empresa uruguaia de abate, processamento e exportação, por US\$ 85,5 milhões. O frigorífico, também uruguaio, La Caballada, foi comprado US\$ 26 milhões. Em suas operações no Chile, a Marfrig comprou o frigorífico Patagonia por US\$ 8,5 milhões, e adquiriu por US\$ 17 milhões a Quinto Cuarto, com a qual já havia estabelecido parceria. No Brasil, a Marfrig efetuou a aquisição do frigorífico brasileiro Mabella, de suínos, iniciando suas atividades no ramo no país. Também adquiriu a processadora de carne (carnes enlatadas e carne desidratada) Pampeano. E por fim, comprou a Kilo Certo, empresa brasileira de processamento de carnes, por R \$ 25 milhões.

Em 2008, a empresa brasileira efetuou a aquisição da Mirab, processadora de carne argentina, por US\$ 36 milhões. Também comprou a CDB Meats Limited, importador e distribuidor de produtos alimentícios do Reino Unido, por US\$ 12 milhões; e a Moy Park (frangos, Irlanda) e Grupo OSI (bovinos, suínos e aves, Estados Unidos) por US\$ 680 milhões. Em suas operações brasileiras, a Marfrig comprou a Carroll’s Food do Brasil, na área de suínos, por R\$ 42,2 milhões; arrendou unidades de suínos em Itararé (SP), com capacidade de 1000 cabeças/dia; adquiriu a DaGranja Agroindustrial, empresa brasileira do ramo de aves, pelo equivalente a US\$ 58 milhões, iniciando suas atividades no ramo de aves no país; e realizou a aquisição da Pena Branca (Moinhos Cruzeiro do Sul e Penapaulo), do mercado avícola, por US\$ 53 milhões.

No ano de 2009, num grande passo para sua estrutura produtiva, a Marfrig anunciou a aquisição da Seara, empresa brasileira de processamento de aves e suínos, por US\$ 706,2 milhões. Também efetuou o arrendamento de 12 unidades de abate e processamento do grupo brasileiro Margem, com capacidade de processamento de 1700 toneladas/dia; a aquisição da unidade de produção de perus da Doux-Frangosul, brasileira, por R\$ 65 milhões; e a aquisição da Zenda, empresa do setor de couros, do Uruguai, por US\$ 38 milhões.

Em 2010 houve a aquisição da norte-americana, processadora de alimentos, Keystone Foods por US\$ 1,26 bilhão; a aquisição da O'Kane Poultry, processadora de aves irlandesa, por $£ 26$ milhões; a construção de área de confinamento na Argentina por US\$ 6,4 milhões; e a aquisição da divisão de legumes e vegetais congelados da Arcor na Argentina, por R\$ 3,4 milhões. Enquanto em 2011 foram anunciadas duas parcerias: uma joint venture com a COFCO, empresa chinesa de distribuição de alimentos, num total de US\$ 252 milhões; e uma joint venture com a Chinawhiz, de processamentos de aves, também chinesa, com US\$ 57 milhões.

Após este período de grandes aquisições, a Marfrig enfrentou problemas operacionais que afetaram seus resultado nos últimos anos. Neste intervalo, a empresa passou por reestruturações operacionais e administrativas, dando novos focos em sua estratégia de ação e negócios. Em 2012, houve um direcionamento do foco da Keystone Foods para as atividades de produção, industrialização e comercialização de alimentos à base de proteínas, vendendo seu negócio de serviços de logística especializada. Em 2013, há uma reestruturação do capital da empresa, por meio da venda das unidades de negócio Seara e Zenda por R \$ 5,85 bilhões para a JBS, iniciando uma nova política organizacional intitulada "Focar para Ganhar". Já em 2014, a Marfrig adotou uma nova denominação social, passando para Marfrig Global Foods S.A, realizando alterações em suas práticas de governança e atingindo as projeções financeiras para o mesmo ano. Em 2015, com sua nova estrutura de governança e um novo projeto corporativo, a empresa realizou a venda da Moy Park por US\$ 1,2 bilhão e a aquisição do Frigorífico Mercosul (Brasil) por R\$ 418 milhões (MARFRIG, 2015)

\subsection{BRF}

A BRF inicia, em 2011, sua expansão para o mercado internacional, por meio da aquisição das empresas Avex e Dánica, companhias argentinas de aves e margarinas, respectivamente, por 
US\$ 150 milhões. No ano de 2012, ela realizou a aquisição da Quickfood, empresa argentina de processamento de alimentos controlada pela Marfrig, numa troca de ativos com a empresa, com uma compensação no valor de R 200 milhões. No mesmo ano, foram mais duas operações: aquisição de participação acionária da Federal Foods, distribuidora de alimentos dos Emirados Árabes Unidos, US\$ 36 milhões, e joint venture com a Dah Chong Hong, empresa chinesa de distribuição, resultando na Rising Star Food Company Limited.

Já em 2014, a BRF intensifica seu processo de expansão, buscando novos ativos na Ásia, por meio de joint venture com a PT Indofood Suskes Makmur Tbk, alimentos processados e aves da Indonésia, e no Oriente Médio, com investimento em nova fábrica de alimentos processados nos Emirados Árabes Unidos, num total de US\$ 160 milhões, aquisição total da Federal Foods, dos Emirados Árabes Unidos, por US\$ 27,8 milhões, aquisição de participação acionária da Al Khan Foods, empresa de distribuição de congelados no Omã, por US\$ 68,5 milhões, e aquisição de participação acionária da Alyasra, empresa de distribuição de congelados no Kuwait, por US\$ 160 milhões.

Já em 2015, houve a aquisição da produtora de aves tailandesa, Golden Foods Siam, por US\$ 360 milhões. No Reino Unido, a empresa realizou duas transações: aquisição da Universal Meats, distribuidora de alimentos no ramo de food service do Reino Unido, por $£ 34$ milhões, e joint venture com a Invicta Food Group Limited, distribuidora de alimentos processados do Reino Unido, por £ 18 milhões. A BRF também expandiu suas operações na Argentina, por meio da aquisição da Eclipse Holding Cooperatief UA, sociedade holandesa que controla a Campo Austral, empresa argentina do mercado de suínos e frios, por US\$ 85 milhões, e da aquisição das marcas Vieníssima, GoodMark, Manty, Delícia, Hamond, Tres Cruces e Wilson, do grupo argentino Molinos, por US\$ 43 milhões. Também houve a realização de outra joint venture, por US\$ 19 milhões, com a Singapore Food Industries, de Cingapura, e a compra de parte da Qatar National Import and Export, distribuidora de congelados dos Emirados Árabes, por US\$ 140 milhões (BRF, 2015).

\subsection{Minerva Foods}

A Minerva Foods é uma das líderes na América do Sul na produção e comercialização de carne in natura e seus derivados, exportação de gado vivo, atuando também no processamento de carne bovina, suína e de aves, com 17 plantas de abate de bovinos sendo 11 localizadas no Brasil, 3 no Paraguai, 2 no Uruguai e 1 na Colômbia, com capacidade total de abate de 17.330 cabeças de gado por dia, e também tem operações em outros segmentos, como biodiesel, embalagens, couros, comércio de animais vivos e logística. A empresa possui uma unidade de processamento de proteínas (Minerva Fine Foods). Suas exportações alcançam mais de 100 países em cinco continentes, com 9 escritórios comerciais e 13 centros de distribuição, dos quais 11 são no Brasil e 2 no Paraguai.

Em 2008, a Minerva realiza sua primeira aquisição no exterior, comprando o frigorífico paraguaio Friasa, por US\$ 5 milhões. Em 2011, após algumas aquisições no Brasil, a empresa realizou a aquisição do frigorífico uruguaio Pul, por US\$ 65 milhões. No ano seguinte, realizou a compra de outra unidade de processamento e abate de bovinos no Paraguai, a Frigomerc, por US\$ 35 milhões. Em 2013, a Minerva Foods se focou no Brasil, realizando a compra de duas plantas de abate e a criação de dois centros de distribuição. Já em 2014, houve a aquisição do Friogorífico Carrasco, do Uruguai, por US\$ 37 milhões. Por fim, em 2015, comprou o frigorífico colombiano Red Cárnica por US\$ 30 milhões e arrendou a Expacar, empresa paraguaia de processamento e abate de bovinos. (MINERVA, 2015).

\section{Análise dos Dados}


Todas as empresas iniciam seu processo de internacionalização com aquisições em países vizinhos, na América do Sul. As empresas JBS e BRF iniciam sua expansão internacional na Argentina; a Marfrig, além do mercado argentino, também realiza investimentos no Uruguai e no Chile; e a Minerva Foods inicia seus investimentos no Paraguai. Este cenário pode ser entendido como a etapa inicial de internacionalização das empresas brasileiras, buscando novos ativos em países próximos e com matérias-primas diferentes.

Numa segunda etapa desta expansão internacional, as firmas optaram por investir em diferentes mercados. A JBS expande suas operações com foco em três grandes localidades: os mercados norte-americano, europeu e da Oceania (em especial, a Austrália). A Marfrig consolida suas operações no mercado sul americano, com mais aquisições na Argentina, Chile e Uruguai, e expande suas operações para o mercado europeu. Já a BRF optou por investir e consolidar sua posição dentro do mercado asiático e do Oriente Médio. Por fim, a Minerva Foods intensificou seus investimento na América do Sul, focando-se no Paraguai, Uruguai e Colômbia.

Com as localidades definidas, observou-se que as empresas também diferem em suas estratégias de produção e posicionamento dentro dos mercados. Tanto JBS quanto Marfrig optaram por consolidar suas posições como produtores de carnes (cortes in natura), direcionando suas aquisições para etapas produtivas de maior valor agregado, como alimentos processados à base de carne (hambúrguer, salsichas, pratos prontos, etc.). Já a BRF tem sua produção de alimentos processados concentrada no Brasil e seus investimentos foram focados na aquisição de centros de distribuição e comercialização no Oriente Médio e na Ásia. E a Minerva Foods manteve seu foco na criação e abate de gado para a produção de cortes in natura.

A primeira empresa a se internacionalizar foi a JBS em 2005, que contou com elevado apoio do governo brasileiro para o financiamento dos investimentos. A segunda empresa foi a Marfrig em 2006, que após diversas aquisições teve que reestruturar sua gestão, reduzindo seus investimentos. A Minerva, em 2008, é a terceira empresa a se internacionalizar e mostra um volume menor de investimento quando comparada às outras três companhias. A BRF inicia mais tardiamente sua expansão internacional, em 2011, pois a empresa é fundada em 2009, resultado de uma fusão entre as empresas brasileiras Sadia e Perdigão.

\section{Considerações Finais}

Independente da direção tomada pelas empresas em seus movimentos de internacionalização, diferentes elementos das diversas teorias discutidas podem ser encontrados. Um exemplo é a teoria do poder de mercado de Hymer, pois mesmo que as empresas iniciem operações visando a criação de nova vantagem competitiva elas se beneficiarão do aumento da participação nos novos mercados. Nesse sentido, vemos que, para o caso do setor frigorífico brasileiro - considerando os quatro casos - as motivações para internacionalização são variadas e se enquadram em diferentes referenciais teóricos.

No entanto, é possível considerar que as diferentes teorias tem origem em diferentes contextos históricos e visam explicar os movimentos de internacionalização de variadas atividades econômicas. Como exemplo, vemos que a teoria do ciclo de vida do produto de Vernon aplica-se de forma mais adequada a indústrias manufatureiras, cujo produto possui algum grau de complexidade tecnológica que justifique as diferentes etapas de internacionalização previstas pelo autor. Apesar de ser possível aplicar uma dinâmica de aprendizado no setor frigorífico, ela possuiria características específicas desse setor, não sendo perfeitamente enquadrada no referencial teórico proposto por Vernon.

A teoria oligopolista de Knickerbocker demonstra diversos elementos presentes no setor frigorífico brasileiro, entre eles a competição existente entre grandes players que se influenciam 
mutuamente de acordo com os movimentos adotados. O fato de as firmas desse setor produzirem bens substitutos (em alguns casos perfeitamente substitutos) evidencia ainda mais a importância das decisões estratégicas de internacionalização. Uma vez que esses movimentos podem representar a oportunidade de criação de vantagens competitivas consideráveis, como a produção de bens de qualidade mais elevada e a superação de barreiras fitossanitárias impostas a países específicos. Nesse sentido, as empresas do setor buscariam a criação dessas vantagens adotando investimentos semelhantes ao first mover, de modo a não perder capacidade competitiva.

A exemplo disto se verifica o movimento inicial da JBS com a busca por uma matéria prima de maior qualidade que a brasileira (carne argentina). Após sua entrada no mercado argentino, as outras empresas realizam o mesmo movimento, ou de maneira semelhante se instalam em localidade próximas a fim de usufruir das mesmas vantagens. Estes investimentos garantem à empresa um produto que terá menores restrições fitossanitárias em sua comercialização. Partindo da América do Sul, as empresas passam a buscar novos destinos para expandir seu mercado, não necessariamente concorrendo nas mesmas localidades, mas realizando simultaneamente investimentos que as garantam maiores parcelas do share mundial por meio do aproveitamento de vantagens competitivas.

De forma semelhante, o paradigma eclético de Dunning trabalha com o conceito de vantagens de localização, o que indica a predisposição das firmas em aproveitarem as oportunidades dadas pelos países para iniciarem o processo de internacionalização. Assim, os movimentos de investimento podem ser complementados por processos de internalização de atividades, uma vez que as firmas, já possuindo domínio das core competences do setor, buscam avançar no domínio do processo produtivo, diversificando suas atividades ao avançar para etapas de diferentes níveis de valor agregado. A internalização, no caso desse setor, não aparenta ocorrer devido a necessidade de evitar as imperfeições de mercado (conforme Buckley e Casson), mas sim em função da diversificação da produção.

A teoria da internacionalização por etapas de Johanson e Vahlne demonstra proximidade com o caso observado. A internacionalização das empresas se inicia dentro da América do Sul com investimentos iniciais em Argentina, Paraguai e Uruguai, ilustrando a pequena distância física entre os países. A sequência da etapa da internacionalização é a ida para mercados que apresentam maiores distâncias física e psíquica, como o norte-americano, o europeu, o asiático, o da Oceania e do Oriente Médio. Por fim, as empresas realizam novos investimentos nos países por intermédio de suas subsidiárias (por exemplo, a JBS realiza aquisições posteriores nos EUA por meio da JBS USA).

Os casos estudados têm suas peculiaridades, de acordo com a estratégia de cada empresa. Chama atenção a velocidade com que ocorreu a internacionalização das empresas, o que pode ser representativa da combinação do apoio de bancos ao financiamento das operações com o fato de as firmas já possuírem vantagens competitivas. Desse modo, as teorias de internacionalização que enfatizavam a existência prévia de vantagens competitivas podem contribuir para explicar a velocidade com que as empresas realizaram sua expansão internacional. Por outro lado, o apoio institucional proporcionado às companhias possibilitou a superação dos obstáculos próprios dos países em desenvolvimento.

Assim é possível observar que as teorias utilizadas para os estudos dos casos tem boa capacidade explicativa quando levantados aspectos específicos. Observou-se que as empresas, em concordância com a teoria da reação oligopolista, se movimentam para mercados estrangeiros seguindo o first mover, para que haja a perda de participação no mercado mundial. Considerando que as firmas realizaram seus investimentos buscando novos ativos e expandiram-se com base em suas competências já estabelecidas, é possível observar o referencial proposto no paradigma eclético de Dunning. Este paradigma ainda é completado pela ideia de internalização proposta por 
Buckley e Casson, mas com discrepâncias ao considerar os quatro casos: as firmas que internalizaram etapas da produção parecem tê-lo feito em função da busca por produtos de maior valor agregado, diferentemente do proposto pela teoria, na qual a internalização ocorre para que sejam suprimidas as imperfeições de mercado.

No caso da teoria de poder de mercado de Hymer é possível aplicá-la a todos os casos estudados. Em compensação, a teoria do ciclo de vida do produto só teria aplicações caso houvesse uma distorção de sua interpretação e seus limites. Este fato é observado em função da peculiaridade deste referencial, pois foi estruturado considerando os diferentes estágios de produção em função da maturação das tecnologias empregadas na indústria de transformação após a Segunda Guerra Mundial.

Este estudo possibilitou a compreensão da dinâmica de expansão internacional do setor frigorífico brasileiro. Assim, sugere-se que ele seja complementado com estudos comparativos para o mesmo setor, considerando-se países que também tenham grande representatividade na indústria frigorífica, de modo que seja possível estruturar um modelo teórico específico à internacionalização do setor frigorífico.

\section{Referências}

ANUALPEC. Anuário Brasileiro da Pecuária 2015. Editora Gazeta, 2015. Disponível em: <http://www.grupogaz.com.br/editora/anuarios/show/4904.html>. Acesso: 16 Jan. 2016.

BELK, Keith E. et al. The meat industry: do we think and behave globally or locally? Meat Science, vol. 98, p. 556-560, 2014.

BRF. Portal de RI. BR Foods. Disponível em: <http://ri.brfglobal.com/default_pt.asp?idioma=0\&conta=28>. Acesso: 16 Jan. 2016.

BUCLEY, Peter J.; CASSON, Mark. A long-run theory of the multinational enterprise. In: BUCLEY, Peter J.; CASSON, Mark (eds). The Future of The Multinational Enterprise. p. 32-65 - London: Macmillan, 1976.

CANTWELL, John. A survey of theories of international production. In: PITELIS, Christos N.; SUGDEN, Roger. (eds). The Nature of the Transnational Firm. 2nd ed. p. 10-56 - New York: Routledge, 2000.

CAVES, Richard E. International Corporations: the Industrial Economics of Foreign Investment. Economica, vol. 38, n. 149, p. 1-27, 1971.

. Multinational Enterprise and Economic Analysis. 3rd ed. - New York: Cambridge University Press, 2007.

CLYMA, Kimberlie. Successful sales: Ranking the industry's top processors. Meat \& Poultry Magazine, p. 16-24, 2014.

DUNNING, John H. The determinants of international production. Oxford Economic Papers, vol. 25, n. 3, p. 289-336, 1973. 
Towards an eclectic theory of international production: Some empirical tests. Journal of International Business Studies, vol. 11, n. 1, p. 9-31, 1980.

. The Eclectic Paradigm of International Production: A restatement and some possible extensions. Journal of International Business Studies, vol. 19, Spring, p. 1-31, 1988.

DUNNING, J. H.; KIM, C.; PARK, D. Old Wine in New Bottles: A Comparison of Emerging Marketing TNCs Today and developed Country TNCs Thirty Years Ago. In. SAUVANT, K. P. (Ed.). The Rise of Transnational Corporations from Emerging Markets. Williston, USA: Edward Elgar Publishing Inc, 2008, p. 158-180.

FDC. Ranking FDC das Multinacionais Brasileiras 2015. 10ª ed. Fundação Dom Cabral. - Nova Lima/MG: FDC, 2015

HYMER, Stephen H. The International Operations of National Firms: A Study of Direct Foreign Investment. PhD Dissertation. 1976 ed. - Cambridge: MIT Press, 1960.

IETTO-GILLIES, Grazia. Transnational Corporations and International Production: concepts, theories and effects. 2nd ed.- Cheltenham: Edward Elgar Publishing, 2012.

JBS. Relações com Investidores. Grupo JBS-Friboi. Disponível em: < http://www2.jbs.com.br/ri/>. Acesso: 05 Dez. 2015.

JOHANSON, Jan; VAHLNE, Jan-Erik. The Internationalization Process of the Firm - A Model of Knowledge Development and Increasing Foreign Market Commitments. Journal of International Business Studies, vol. 8, n.1, 1977.

11-24, 1990.

. The Mechanism of Internationalization. International Marketing Review, vol. 7, n. 4, p.

JOHANSON, Jan; WIEDERSHEIM-PAUL, Finn. The internationalization of the firm: four Swedish cases. Journal of Management Studies, vol. 12, n. 3, p. 305-323, Oct, 1975.

KNICKERBOCKER, Frederick T. Oligopolistic Reaction and Multinational Enterprise. Cambridge: Harvard University Press, 1973.

KUMAR, Vikas; SINGH, Nitish. Internationalization and performance of Indian pharmaceutical firms. Thunderbird International Business Review, vol. 50, n.5, p. 321-330, Sep/Oct, 2008.

MARFRIG. Relatório Anual 2014. Marfrig Global Foods. Disponível em: <http://ri.marfrig.com.br/Upload/Arquivos/Marfrig_RA14.pdf>. Acesso: 07 Dez. 2015

MCMANUS, John. The Theory of the International Firm. In: PAQUET, Gilles (ed.). The Multinational Firm and the Nation State, p. 66-93. Don Mills: Collier-Macmillan, 1972. 
MINERVA. Relação com Investidores. Minerva Foods. Disponível em: $<$ http://ri.minervafoods.com/minerva2012/web/default_pt.asp?idioma=0\&conta=28\&v=1\#>. Acesso: 15 Jan. 2016.

NARULA, Rajneesh. Do multinationals matter for emerging markets, or vice-versa? In: DOLFSMA, Wilfred; DUYSTERS, Geert; COSTA, Ionara (eds.). Multinationals and Emerging Economies: the quest for innovations and sustainability. p. 75-77 - Cheltenham: Edward Elgar, 2009.

PEARCE, Robert; PAPANASTASSIOU, Marina. Subsidiaries, Innovation and the Strategic Development of Multinationals. In: PEARCE, Robert; PAPANASTASSIOU. The Strategic Development of Multinationals: subsidiaries and innovation. p. 1-20 - New York: Palgrave Macmillan, 2009.

PIMENTEL, Vitor P. et al. Inserção internacional das empresas farmacêuticas: motivações, experiências e propostas para o BNDES. BNDES Setorial, Rio de Janeiro, n. 40, p. 5-42, Set. 2014

ROVAI, Ricardo; PISCOPO, Marcos R.; MACCCARI, Emerson A. Innovation in the strategies of internationalization of the Brazilian multinationals: Evaluation of the cultural national dimensions: A study case of the meat processing sector. International Journal of Innovation, vol. 1, p. 62-81, 2013.

SPOHR, Nicole; SILVEIRA, Franciane F. Estratégia Internacional de uma Multinacional Emergente Brasileira: o caso JBS. Revista de Administração de Empresas, vol. 52, n. 3, Maio/Junho, p. 300-312, 2012.

VERNON, Raymond. International investment and international trade in the product cycle. The Quarterly Journal of Economics, vol. 80, n. 2, p. 190-207, 1966. 